\title{
LA CONTRALORÍA GENERAL DE LA REPÚBLICA DE CUBA
}

Alcides Antúnez-Sánchez Amed Ramírez-Sánchez 
Panorama Económico, 24 (Octubre 2016 - Septiembre 2017), pp. 175-204

Alcides Antúnez-Sánchez

Amed Ramírez-Sánchez

\title{
La Contraloría General de la República de Cuba
}

\section{Resumen}

El presente artículo muestra un estudio del control administrativo realizado a los organismos de la Administración Pública por el órgano de control supremo constituido en Cuba, a partir del análisis histórico, teórico, legislativo del desarrollo y evolución del control a través de la auditoría pública y la función inspectiva con acciones de control gubernamental y fiscalización. Para ello se realiza un análisis del desarrollo que ha tenido la ordenación jurídica del control público y de los mecanismos que han sido implementados en cada etapa, dirigidos en esencia al control del patrimonio del sector estatal; al ser este mayoría, y la necesidad de su reconocimiento en la Constitución de la República. A tales efectos, para desarrollar todo este análisis se utilizaron los métodos teóricos de investigación como el exegético-jurídico, el histórico-lógico, el de inducción-deducción y el de análisis-síntesis.

Palabras Clave: Auditoría pública, función inspectiva, fiscalización, Estado vigilante.

Clasificación JEL: M40, M41, M42, M48, M49.

\section{The comptrollership in the republic of Cuba}

\begin{abstract}
This article presents a study about the administrative control applied in the Public Administration by the supreme body of control constituted in Cuba. To carry out this study, we used the historical, theoretical, and legislative analysis about the development and evolution of comptrollership using the public audit regarding the inspection function with actions related to the government control and inspection. Since a recognition of the State heritage in the Constitution of the Republic is necessary, we ran an analysis of the development that the legal ordering of public control has had, and about the mechanisms that have been implemented at each stage, directed essentially at the control of the State sector's heritage. To conclude, we used certain theoretical research methodologies such as the legal-exegetical, the logic-historical, the induction-deduction and the analysis-synthesis analysis.

Keywords: Public audit, inspection function, surveillance state, inspection.
\end{abstract}

JEL Classification: M40, M41, M42, M48, M49.

\section{Le contrôleur général de Cuba}

\section{Résumé}

Cet article étudie le contrôle administratif appliqué aux instances de l'Administration Publique par l'organe suprême de contrôle de Cuba d'un point de vue historique, théorique et législatif en considérant le développement et l'évolution du contrôle gouvernemental. Il est nécessaire de reconnaître le patrimoine de l'État dans la Constitution de la République, nous avons analysé le développement que l'ordre juridique du contrôle public a eu et les mécanismes qui ont été mis en œuvre à chaque étape, essentiellement dirigés vers le contrôle du patrimoine du secteur public. De plus, nous avons utilisé certaines méthodologies de recherche théorique telles que la logiqueexégétique, la logique-historique, l'induction-déduction et l'analyse-synthèse.

Mots-clés: Évaluation publique, fonction d'inspection, état surveillance, inspection.

Nomenclature JEL: M40, M41, M42, M48, M49. 
Artículo de Revisión

\section{LA CONTRALORÍA GENERAL DE LA REPÚBLICA DE CUBA}

INFORMACIÓN DEL. ARTÍCULO

Recepción de artículo: 5 de abril de 2016

Aceptación de artículo: 20 de agosto de 2016
Alcides Antúnez-Sánchez Universidad de Granma

Cuba

Amed Ramírez-Sánchez Universidad de Oriente

\section{PRÓLOGO}

Cuba, en su condición de Estado socialista, al amparo del texto constitucional, impone la regulación de mecanismos de control para garantizar la adecuación de los poderes públicos que la propia Constitución es garante para el correcto uso del patrimonio público. El desarrollo social de las últimas décadas ha sido un factor determinante en la definición del rol de lo público como mecanismo de dirección y control social.

Esta situación se debe en buena medida a que el contenido de la actividad administrativa y la propia concepción de la Administración Pública han sido dos conceptos variables y no uniformes, consustanciales con el tiempo, al escenario geográfico, al régimen sociopolítico y en especial referencia dentro de este, a la intervención del Estado en las relaciones sociales en sus distintas modalidades.

A la Contraloría General, luego de su creación le corresponderá velar por la buena gestión y la juricidad del patrimonio público, al ejercer el control fiscal. En el ordenamiento jurídico cubano el texto constitucional adolece del reconocimiento tácito de este órgano supremo de control, lo que le resta garantía constitucional de su autonomía como órgano constitucional, como parte del poder ciudadano. Ello permite afirmar que la Contraloría General no es Administración Pública, aunque el control sea parte de la función administrativa. El objetivo es demostrar la necesidad de reconocer a la Contraloría General dentro del texto constitucional en relación con la actividad de control administrativo que esta ejecuta como órgano de control, a partir de su evolución histórica y normativa que han tenido los mecanismos de control público en la nación cubana.

${ }^{1}$ Autor para correspondencia. Correo electrónico: aantunez@udg.co.cu; antunez63@nauta.cu; aramirez@udg.co.cu 


\section{CRITERIOS DOCTRINALES ACERCA DEL CONTROL PÚBLICO}

La doctrina del Derecho Púbico señala que el asidero jurídico del órgano de control público que ejercita la función inspectiva y la auditoría pública se regula en el texto constitucional en el Estado de Derecho, ello permite demostrar la existencia de mecanismos de control que hacen efectivos los principios y valores en el desarrollo normativo del Estado. El control en sí, es uno de los elementos que integran y definen el Estado de Derecho y el Estado democrático. Este control, desde una perspectiva conceptual, no es más que la actividad de "comprobación, inspección, fiscalización, e intervención", lo que en el ámbito jurídico se expresaría en "un acto o procedimiento por medio del cual una persona o un órgano debidamente autorizado para ello examina o fiscaliza un acto realizado por otra persona u órgano, a fin de verificar si en la preparación y cumplimiento de dicho acto se han observado todos los requisitos que exige la ley".

La doctrina señala que el concepto del control constituye uno de los paradigmas de la democracia incorporada al Estado, y la norma jurídica es el límite del control de poder, lo hace susceptible de su verificación, por lo que es sustancial en la democracia. Por ello el derecho es un elemento difícil de conceptualizar; a partir de su etimología se constata que existen diversas palabras que le definen como: rectus, directius, justitia, jus, juris, rectum, aequm, atis, todas ellas refieren derecho, recto, justicia, equidad, etc. Ya en Roma se le señalaba como ars boni et aequi.

Kelsen, definió al control como un orden coactivo de la conducta humana'. García

1 KELSEN, Hans, Teoría general del Derecho y del Estado, $2^{\text {da }}$ edición, UNAM, México, 1988, pp.22 y ss.
Máynez, considera que es un conjunto de normas impero-atributivas que en cierto momento histórico y en un determinado territorio, quienes detentan el poder juzgan obligatorias para el resto de la colectividad $^{2}$.

Dworkin estimó que el Derecho es un concepto interpretativo. ${ }^{3}$ Desde la perspectiva de la Sociología, se analiza lo que señala Lasalle, quien considera que la Constitución es la suma de factores reales de poder que se trocan en factores jurídicos, para este autor el Derecho es la suma de los factores reales del poder. ${ }^{4}$

Entonces, el control no es más que el vehículo efectivo de la limitación del poder, considerando, dentro de éste, a todas las formas e instrumentos que posee el sistema político y jurídico para supervisar el ejercicio de los poderes públicos, se expresa en actos o normas a partir del texto constitucional, entendiendo que estas últimas son una expresión precisamente de su actividad jurídica a través del desarrollo normativo, el mismo es ejecutado por la Administración Pública a través de los órganos que la misma les otorga este ejercicio del poder público.

La etimología latina le define desde la época medieval como contra rotulum, en Francia se le consideró como contre-lore (contralibro) -libro registro-, término que con el trascurrir del tiempo se popularizó hasta definirlo con las definiciones de fiscalizar, dominar, someter, etc. El catedrático Cabanellas consideró que el termino de control es mejor reconocerle como: comprobación,

2 GARCÍA MÁYNEZ, Eduardo, Introducción al estudio del Derecho, 41 a edición, Editorial Porrúa, México, 1990, p.37 3 DWORKIN, Ronald, El imperio de la Justicia, Editorial Gedisa, España, 1988, pp.72, 287-288.

4 LASALLE, Ferdinand, ¿Qué es una Constitución?, Editorial Panamericana, Colombia, 2002, pp.14-15 
fiscalización, intervención, registro, vigilancia, mando, gobierno, predominio, hegemonía, supremacía, dirección, guía, freno, contención, regulador, factor, causa. ${ }^{5}$

Su naturaleza jurídica está concebida a partir de que el control es un sistema de verificación y corrección de la legalidad que evalúa el principio de juridicidad, está directamente vinculado al concepto de Estado de Derecho, y ciertamente se relaciona asimismo, con la democracia como forma política de gobierno nacional. Sus características serían: esta requerido para su ejercicio de la independencia necesaria que le otorga el modelo democrático, traducido en una serie de garantías como son: independencia, objetividad y respeto para la realización de esta labor, al señalarse por Márquez Piñeiro. ${ }^{6}$

En sí, el control es un mecanismo de contención para la extralimitación en el uso de los poderes públicos, que se constituye en un amparo para los administrados. En el marco de un Estado de Derecho, implica que la Administración en su organización, funcionamiento, relaciones con la comunidad y su personal, están subordinados al ordenamiento jurídico, el que deriva directamente de un marco constitucional. Las normas jurídicas deben someterse a la Constitución Política, y a éstas deberán someterse a su vez, las normas que derivan de la potestad reglamentaria.

Entonces el Derecho, analizado desde la perspectiva del control, es considerado como una herramienta y a la vez una técnica. Es instrumental toda vez que

5 CABANELLAS DE TORRES, Guillermo, Diccionario Jurídico Elemental, $11^{\text {na }}$ edición, Editorial Heliasta S.R.L., España, 1993.

6 MÁRQUEZ PIÑEIRO, R. 2003. Teoría de la antijuricidad. Instituto de Investigaciones JurídicasUNAM. México. juridifica las conductas impuestas como obligatorias a los agentes sociales, en especial a los agentes de la sociedad, en particular a sus servidores públicos al imponerle márgenes de actuación que los convierte en sujetos obligados y por ende en objetivos de control por excelencia. Como técnica, el derecho delimita los procesos, métodos y formas de actuación de los entes controlados cuando estos ejecutan sus actividades, al decir de De Luca y Márquez Gómez. ${ }^{7}$

El control considera la posibilidad de que los órganos de la Administración, al ejercer sus potestades, comprometen los intereses y el patrimonio del Fisco, los que están destinados a procurar el interés general y el bien común, y eventualmente pueden afectar los derechos de particulares. Y precisamente, para evitarlo es que el ordenamiento jurídico contempla el control. En su ejecución se debe ser imparcial para que el juicio intelectual que se haga de un acto y de los hechos que configuran sus circunstancias, derivado de un análisis jurídico lógico y racional, sea justo para el espíritu del ordenamiento jurídico, o de la norma específica que clara y directamente le resulta aplicable al sujeto controlado.

Los autores aprecian como a lo largo de su historia, que la labor de control de la Administración Pública ha estado ligada a los actos de corrupción; se afirma por Márquez Gómez que la corrupción es tan antigua como la humanidad; conductas como la perversión de la justicia, el causar dañoa mujeresy niñosyla toma de shohadh

7 DE LUCA, J. 1997. Introducción al Derecho. España. Ediciones Tirant Lo Blanch; MÁRQUEZ GÓMEZ, Daniel, Función jurídica del control de la Administración Pública, serie doctrina jurídica, número 242, Instituto de Investigaciones Jurídicas-UNAM, México, 2005, pp.5-48 
o regalos, acciones que son condenadas por la Biblia, en el Código de Manú y en el de Hammurabi. En Grecia y Roma, cunas de la civilización occidental, se sufrió también el flagelo de la corrupción. En la primera los sofistas hacían de lo negro, blanco y de lo blanco, negro; en la segunda el pretor Verres, quien dictaba sus sentencias según el dinero que le era ofrecido por las partes, son un claro ejemplo de ello. En su Divina Comedia Dante condena a los barattieri, esto es, a los que aceptan dinero o a los jueces que venden la justicia; tampoco se puede olvidar el gran problema de la simonía, que se da durante la Edad Media con la venta de indulgencias en el seno de la Iglesia Católica. ${ }^{8}$

El artículo aborda el control administrativo no jurisdiccional, el que puede desde la doctrina del Derecho Público ser interno o externo, y ser preventivo o a posteriori. Puede a su vez realizarse de propia iniciativa del órgano contralor, o por requerimiento o denuncia de algún interesado. Este tipo de control puede estar orientado a la legalidad, al uso de los recursos, y también al cumplimiento de planes y programas, respecto de sus metas y objetivos que el órgano de control lo tenga concebido.

En relación al vínculo que se constata las relaciones que existen entre la materia del control a partir del Derecho Constitucional como su asidero principal, con el Derecho Administrativo por las técnicas que de este se apropia, con el Financiero para el control de las finanzas públicas y con el Ambiental por ser un bien de uso colectivo, al estar vinculados al control administrativo que ejecutan los servidores públicos, tal y como se señalara por Delgadillo Gutiérrez, y Sánchez Morón. ${ }^{9}$

8 MÁRQUEZ GÓMEZ, ibídem p.2

9 DELGADILLO GUTIÉRREZ, L. 2011. El sistema de
Así las cosas, por ser el derecho unitario, a partir de las demás ramas que lo integran y lo componen desde las Ciencias Jurídicas, esta función de control parte desde la Constitución. Para ello, se realiza el análisis de la labor que ejecuta la Contraloría General como órgano de control, este órgano efectuará auditorías con el objeto de velar por el cumplimiento de las normas jurídicas, el resguardo del patrimonio público y la probidad administrativa de los sujetos auditados. Procederá a hacer evaluaciones de los sistemas de control interno; fiscalizará la aplicación de las disposiciones relativas a la administración financiera del Estado, particularmente, las que se refieren a la ejecución presupuestaria de los recursos públicos; examinará las operaciones efectuadas y la exactitud de los estados financieros; verificará el cumplimiento de las normas estatutarias aplicables a los funcionarios públicos y formulará las proposiciones que sean adecuadas para subsanar los vacíos que detecte, al decir del criterio de Aldunate, Hernández y Lanz Cárdenas. ${ }^{10}$

Se apropia en su actuar de principios desde el Derecho Administrativo como el de centralización, descentralización y la desconcentración, al ejecutar la función de policía administrativa o coacción, de servicios públicos y de fomento para alcanzar determinados fines, denominado desde la doctrina como acto jurídico,

responsabilidades de los servidores públicos. México: Ediciones Porrúa; SÁNCHEZ MORÓN, M. 1991. El control de las Administraciones Públicas y sus problemas. Madrid. Ediciones Espasa-Calpe S.A. 40

10 ALDUNATE L., E. 2005. "La evolución de la función de control de la Contraloría General de la República". Revista de Derecho de la Pontificia Universidad Católica de Valparaíso. XXVI. Chile: 19-30; HERNÁNDEZ, J. 2000. "La Contraloría General de la República". Revista de Derecho Público. 83. Venezuela; LANZ CÁRDENAS, J. 1987. La contraloría y el control interno en México. México. Ediciones Fondo de Cultura Económica. 
ejecutado por las Contralorías, los Tribunales de Cuentas y por las Sociedades Mercantiles. Los autores, al analizar lo señalado por Serra Rojas, quien refiere que los fines del Estado constituyen direcciones, metas, propósitos, o tendencias de carácter general para su justificación consagradas en la legislación y evaluar la juricidad. Se valora que lo planteado por este autor son los medios y formas que adopta la Administración para lograr sus fines. ${ }^{11}$

Empero, el control de la juridicidad, el que no es ajeno al ciudadano, ya que precisamente es el objeto principal de los resguardos que tiene el Derecho para la satisfacción de las necesidades públicas y de sus derechos garantizados constitucionalmente. De esta manera, el Derecho Administrativo se aprecia que se ha desarrollado en el último tiempo aumentando las posibilidades de que la propia comunidad ejerza un control directo sobre la Administración, poniendo un equilibrio adecuado entre las potestades públicas, los fines de la Administración, y los derechos de los administrados, ponderadas para el control de los actos de corrupción administrativa y el lavado de activos, al decir de autores de la talla de Nieto, Garrido Falla, Villar Palasí, Gordillo, Delpiazzo, Parejo Alfonso y Márquez Gómez. ${ }^{12}$

11 SERRA ROJAS, Andrés, Derecho Administrativo, 27 edición, Editorial Porrúa, México, 2007.

12 NIETO, Alejandro, Algunas precisiones sobre el concepto de policía, editorial Universidad Autónoma de Barcelona, España, 1999, pp.1-74; DELPIAZZO, Carlos, Tribunal de Cuentas, Editorial AMF, Montevideo, 1982, p.76; PAREJO ALFONSO, Luciano, y otros, Manual de derecho administrativo, Editorial Ariel, Barcelona, 2014; MÁRQUEZ GÓMEZ, Daniel, Los procedimientos administrativos materialmente jurisdiccionales como medios de control de la Administración Pública, Instituto de Investigaciones Jurídicas, Serie Estudios Jurídicos, número 20, $1^{\text {ra }}$ edición, UNAM, México, 2003, pp.27-45
Se justiprecia que este aparece ante el incremento del fenómeno de la corrupción, el que ha obligado a buscar los caminos para su control, mal endémico de las sociedades actuales en el siglo XXI. En principio se aprecia que los controles fueron de tipo jurídico, pero con la evolución de las entidades económicas se han refinado hacia las formas de corrupción y se requieren, para hacerle frente, otros nuevos controles, tal y como lo viene señalando Delpiazo en sus estudios académicos. ${ }^{13}$

Así, instituciones como la partida doble que ya aparece en algunos libros en 1340, señalada por Paciolus, conocido como fray Luca Pacioli (1445-1517), en su libro "Suma de Aritmética, Geometría y Contabilidad", va a ser consideran los autores el antecedente de los modernos auditores y de la contabilidad. También en la Magna Charta de 1215 , tiene como eje el motor los abusos del monarca inglés. La Ilustración, con su llamado a la razón, pone el acento en el control del poder. La teoría de la división de poderes, que en esta época adquiere relevancia, tiene como propósito que el poder controle al poder. Son analizados los conceptos vinculados al control administrativo, como la Comprobación, para examinar o confirmar algo, y con ello comprobar la veracidad y exactitud. La Fiscalización, concepto que proviene de fiscalizar, entidades o actividades para comprobar si pagan impuestos o examinar, controlar o criticar las actividades de otros. Y la Inspección, como la acción y el efecto de inspeccionar, examinar algo para determinar su estado, en busca de personas o cosas, al decir de autores como Aragón y Cabanellas. ${ }^{14}$

13 DELPIAZZO, Carlos, Desafíos actuales del control, Editorial F.C.U., Montevideo, 2001.

14 ARAGON REYES, Manuel, Constitución y control del poder, Ediciones Ciudad Argentina, Buenos Aires, 1995; CABANELLAS DE TORRES, Ibídem $p .2$ 


\subsection{Algunos criterios doctrinales del control público en América Latina}

Los autores a partir de definir la etiología del control y su relación con el Derecho, le identifican por las voces latinas inspectio, inquisitio, espectactio, onis y judicium, estas se asemejan con examen, regulación, limitación, dispositivo, verificación, tutela, dominio y supremacía. En la enciclopedia del Derecho, autores como Giorgio Berti y Leopoldo Tumiati refieren que el control consiste en un poder de supremacía que le corresponde al Estado como titular de esta soberanía. ${ }^{15}$

La doctrina jurídica reconoce al control como la actividad registral o técnica, encomendada a una función pública, un ente administrativo o estatal o a un empleado público, por el orden jurídico, que se dirige a revisar la adecuación y legalidad de los actos que son encomendados a los diversos órganos del control público, con la obligación de pronunciarse sobre ellos. Para ello Lara Ponte, considera que el control es una herramienta para asegurar que las actividades de los órganos del Estado se ajusten a la juridicidad, para advertir su desempeño institucional y optimizar resultados, alcances y evitar desviaciones, retroalimentando al sistema a través de la toma de decisiones preventivas y correctivas, con un objetivo contribuir a la armonía entre la planificación y la administración de los recursos. ${ }^{16}$

La Intosai, lo ha concebido como: "El control no representa una finalidad en sí mismo, sino una parte imprescindible de un mecanismo regulador que debe señalar oportunamente

15 Enciclopedia de Derecho, OMEGA, Argentina, 1985. 16 LARA PONTE, Rodolfo, Naturaleza jurídicaadministrativa de los órganos de control, perspectivas actuales del Derecho, ensayo jurídico en tiempos de cambio, Editorial ITAM, México, p.510 las desviaciones normativas $\mathrm{y}$ las infracciones de los principios de legalidad, rentabilidad, utilidad y racionalidad de las operaciones financieras, de tal modo que puedan adoptarse las medidas correctivas convenientes en cada caso, determinarse la responsabilidad del órgano culpable, exigirse la indemnización correspondiente o adoptarse las determinaciones que impidan o por lo menos, dificulten la repetición de tales infracciones en el futuro"17. Tal y como se señalara por López Hernández.

Para Lerner, "el control público constituye una institución fundamental del Estado democrático de Derecho. Adquiere su total dimensión, y sentido dentro de un régimen de libertades y democracia, donde el ejercicio del poder público está a cargo de diferentes órganos que constituyen la estructura fundamental del Estado y que se controlan entre sí, de acuerdo con las competencias que les asigna respectivamente la institución"18

Para Licciardo, "el control es la comparación entre el deber ser, conforme a la naturaleza y las normas, con lo que en realidad es". Dromi, concibe que gobierno y control es la fórmula orgánica de la estructura futura del poder, para que a los que mandan no les falte poder y a los que obedecen no les falte libertad, resguardada mediante controles idóneos, que aseguren calidad y eficacia. ${ }^{19}$

Delpiazzo, sostiene que los elementos claves en la realización de la actividad de

17 INTOSAI, Estado de la auditoría ambiental en la comunidad de las EFS, aspectos salientes de la $5^{\text {ta }}$ encuesta sobre la auditoría ambiental, 2007.

18 LERNER, Emilia, El Control Externo gubernamental. En Lecturas sobre Administración Financiera del Sector Público. Ángel Ginestar (compilador), volumen I-Notas Introductorias, CITAF-OEA, Buenos Aires, 1996.

19 DROMI, Roberto, Tratado de Derecho Administrativo, $7^{\text {ma }}$ edición, Editorial Ciudad, Argentina, 1998. 
control son el órgano controlador, el fin perseguido, la estructura, el procedimiento, y los medios; y aunque no menciona el fin en esta enumeración, sí lo hace cuando se refiere a los objetivos de dicho quehacer. Refiere que tan variados como los términos, resultan las clasificaciones doctrinales para la actividad de control, resultando sólo referidas aquellas manifestaciones que se han encargado de la fiscalización de los actos resultantes de una actuación discrecional por parte de la Administración. ${ }^{20}$

Para Giménez Icarrons, las relaciones de control se fundamental en base al aseguramiento de que el ente controlado se adecua en el empleo de sus medio y actuación al fin propuesto y la protección del interés público. ${ }^{21}$

Por control, Waline, entiende que es la verificación de la conformidad de una acción (en la especie, es una actividad administrativa) con una norma que se impone a ésta; esta norma puede ser jurídica (control de regularidad) o una norma de correcta ejecución (control de rentabilidad o de eficacia). ${ }^{22}$

Márquez Gómez, define al control como la función realizada por órganos formal y materialmente administrativos, este consiste en el uso de medios jurídicos para anular o rectificar la gestión pública ilegal o ineficaz. Para ello utiliza procedimientos administrativos que son controles administrativos con auditorías y procesos para determinar la juridicidad de los actos

20 DELPIAZZO, Carlos, Derecho Administrativo uruguayo, Editorial Porrúa, México, 2005, p. 417

21 GIMÉNEZICARRONS, E., Loscontroles administrativos sobre los entes locales, Generalitat de Catalunya, Institut d’Estudis Autonómics-Marcial Pons, Ediciones Jurídicas y Sociales S.A, Madrid, 2001, p.293.

22 WALINE, Marcel, Précis de droit admimstratif, Paris, 2006. p.11 y ss. de las autoridades administrativas. Por su trascendencia es preventivo pero es de naturaleza correctiva, pudiendo ser represivo y sancionatorio. ${ }^{23}$

El control ha transitado y evolucionado en la historia, a partir del nacimiento del Parlamento: Control=>Juzgar, después de la aparición del Parlamento: Control y Jurisdicción => Tribunal de Cuentas y en el Estado Moderno: el órgano de control se relaciona con el Parlamento. Es necesario entonces reseñar que en el mundo las instituciones del control externo, sus principales modelos en el orden internacional y nacional se reconocen en: Tribunal de Cuentas o Corte de Cuentas, sus características van a ejecutar funciones jurisdiccionales, y en algunas ocasiones ejecutan funciones sancionatorias y de legitimación procesal. (Unión Europea, Europa continental, y en Argentina). Contraloría General o Auditoría General, como modelo angloamericano, sus características es a través de dictámenes e informe (Estados Unidos, Canadá, Reino Unido, Emiratos Árabes, Suecia), reconocido como un acto administrativo, señalado por autores como Lanz Cárdenas, Cagnoni, Vázquez Alfaro, Rodríguez Azcué y Cordero Vega.

Moreno, considera que las corrientes doctrinarias modernas están dirigidas en las que priorizan las cuestiones jurídico formales y la determinación de la responsabilidad administrativo contable. La otra corriente fija su atención en el perfeccionamiento de técnicas de los sistemas de información para la toma de decisiones en materia de Administración Financiera, toda vez que el control

23 MÁRQUEZ GÓMEZ, Daniel, Los Procedimientos Administrativos materialmente jurisdiccionales como medios de control en la Administración Pública, UNAM, México, 2002. 
público no se ejerce por desconfianza, no es represivo, no busca argumentos de oposición y no se ejecuta por mera curiosidad.

Es una parte importante de gobernar en su rol como Estado vigilante ${ }^{24}$. Sus características constatan los autores que se identifican por su universalidad, continuidad, obligatoriedad, y la interdisciplinariedad. Ello le permite ser más eficaz cuando hay una mayor independencia de los órganos que lo ejercen. Está concebido que el Control se ejecuta por el Poder Legislativo, este lo realiza directamente o con el auxilio de uno o varios organismos dependientes de él; el Poder Ejecutivo lo ejecuta directamente o con el auxilio de uno o varios organismos de control. Estos órganos u organismos se reconocen dentro de la doctrina del Derecho Público como Tribunal de Cuentas, Contraloría General, Auditoría General, Fiscalía General, y Defensor del Pueblo entre otros. Obedecen a la clasificación siguiente: por las disciplinas que lo sustentan: de la política, del derecho, de la economía, de la contabilidad pública y de la administración, por los poderes que ejerce: legislativo, judicial y ejecutivo, por el momento: preventivo, concomitante y posterior, por la ubicación del órgano controlante: interno y externo, por su actividad: permanente, periódico y accidental, por su intensidad: parcial e integral, por su alcance: de legalidad o formal y de mérito o sustancial, y por las técnicas aplicadas, al consensuarse por autores como Lanz Cárdenas, Delpiazzo Rodríguez, Hernández, y Antúnez Sánchez. ${ }^{25}$

24 EMBID IRUJO, A. 1999. "El rol del Estado: Vigilante o Gestor". Revista de Política Ambiental y Desarrollo Sostenible. Madrid.

25 LANZ CARDENAS, Ibídem no. 10; DELPIAZZO RODRÍGUEZ, C. 1982. Tribunal de Cuentas. Montevideo. Ediciones Amalio Fernández; HERNÁNDEZ, J. 2000. "La Contraloría General de la República". Revista de Derecho Público. 83. Venezuela; ANTÚNEZ SÁNCHEZ, A. 2015. "La auditoría practicada por la
Los mecanismos de control como medios al servicio social son implementados por el Poder legislativo, a través de: Comisiones investigadoras, Juicio Político, Pedidos de informes, Interpelaciones ministeriales. El Poder judicial: Institucionalidad de las Leyes, Habeas corpus, Acción de amparo, Revisión de actos administrativos, Amparo por mora de la Administración. Y por el Poder ejecutivo: inspecciones, homologación de actos, recursos jerárquicos, controles técnicos y administrativos. Para el pueblo en general: quejas y reclamos, referéndum, veto popular y el sufragio, tal y como lo refiere Sánchez Morón. ${ }^{26}$

La doctrina jurídica ha considerado una serie de clasificaciones para el control, Loewstein, ha señalado que existen controles horizontales que operan en el cuadro del aparato estatal y los verticales que operan para el enfrentamiento a la sociedad. ${ }^{27}$

Hay otra clasificación que se dirige al control orgánico del Estado, esta los concibe como legislativo, ejecutivo o administrativo y jurisdiccional. Por su parte Valadés significa queel control según su naturaleza es obligatorio y potestativo, a partir de la valoración de los agentes encargados de su ejecución. Por su objeto este puede ser constructivo y limitativo. Por sus efectos son vinculatorios e indicativos. En relación a su frecuencia puede ser sistemático y esporádico. Por su forma puede ejecutarse de manera verbal

Contraloría General de la República de Cuba. Las formas de actividad administrativa en la actualización del modelo económico cubano para el futuro ordenamiento jurídico en el desarrollo del Derecho Ambiental patrio". Revista Temas Socio-Jurídicos. 68. Colombia: 25-37.

26 SÁNCHEZ MORÓN, Miguel, El control de las Administraciones Públicas y sus problemas, Editorial Espasa- Calpe S.A, Madrid, 1991, p. 40

27 LOEWSTEIN, Karl, Teoría de la Constitución, Editorial Ariel, España, 1976. 
y formal. De acuerdo con los agentes puede ser realizado de forma colectiva o selectiva. Y según sus destinatarios puede ser general y singular. Concluyendo que por su oportunidad los clasifica en previos, progresivos y posteriores. ${ }^{28}$

Los autores valoran que la clasificación realizada por Valadés es la más completa e integral desde su análisis por la doctrina del Derecho Público, toda vez que agrupa todos los elementos a tener en cuenta por la Administración Pública para ejecutar el control administrativo. Para ello apreciamos también lo señalado por Trinidad Lanz Cárdenas, quien refirió que los elementos esenciales del control administrativo son el sujeto, el objeto, la forma y su finalidad. ${ }^{29}$

Es por ello que el objeto del artículo se centra en el control ejecutivo o administrativo, este se deposita en el Poder Ejecutivo y se ejerce a través de una serie de unidades administrativas especializadas, denominadas Contralorías, toda vez que se conforma a través de una Contraloría General y en cada división territorial administrativa se concibe una de ellas, bajo el principio administrativo de centralización y descentralización, para constatar la juridicidad del actuar de los entes de la Administración Pública, expresado en su conclusión en un documento público, apreciándose los principios del Derecho Administrativo como el de centralización, descentralización, y desconcentración, al decir de Garcini Guerra, Parejo Alfonso, García Enterría y Lozano Miralles. ${ }^{30}$

28 VALADÉS, Diego, El control del poder, $2^{\text {a }}$ edición, Ediciones Porrúa-UNAM, México, 2000.

29 TRINIDAD LANZ CÁRDENAS, José, La contraloría $y$ el control interno en México, Fondo de Cultura Económica, México, 1987, pp. 471 y ss.

30 GARCINI GUERRA, H.1986. Derecho Administrativo. La Habana. Ediciones Pueblo y Educación; PAREJO
Arias Gayoso, considera que el principio de legalidad cumple una función cardinal en relación al otorgamiento de potestades imprescindibles para el actuar administrativo, consagrando a la norma jurídica como límite y condición. La Administración podrá actuar hasta donde el ordenamiento le permita, pudiendo regular sobre aquellas materias que se le atribuyan y sólo si se le ha conferido la potestad para hacerlo. ${ }^{31}$

Este principio de legalidad es considerado por los autores como el hilo conductor por el cual se ha de regir la actuación administrativa, se articula la noción de la responsabilidad, se organiza el control y se potencian los derechos de los ciudadanos frente al actuar de la Administración Pública. Los elementos que fundamentan la realización de control: la legitimidad de la acción y el ajuste a la finalidad prevista, o sea, la verificación de la competencia del órgano, los medios, el procedimiento y los fines entran en un proceso de uniformidad y equivalencia.

La actividad controladora se determina por el examen de la actividad administrativa a la luz de su legitimidad, esta última vista desde su regularidad jurídica, no sólo con respecto a las normas establecidas, sino también a los principios que deben orientar la conducta del ente administrativo actuante, así como, la manera en que da respuesta a la finalidad declarada. Con

ALFONSO, L. 2013. Derecho de los bienes públicos. Cizur Menor. Ediciones Aranzadi; GARCÍA DE ENTERRÍA, E. 2006. Curso de Derecho Administrativo. España. Ediciones Thompson-Civitas; LOZANO MIRALLES, J. 1996. Configuración e independencia de los Órganos de Control Externo: un análisis comparado. España. Editorial Civitas.

31 ARIAS GAYOSO, Grethel, Del nuevo Derecho Administrativo: Participación y control popular en la gestión pública. Participación Política, reflexiones desde el Sur, tomo II, $1^{\text {ra }}$ edición, Editorial Advantlogic, Ecuador, 2014. 
respecto al resultado, la actividad de control puede manifestarse de dos formas: una primera, restrictiva, por la cual una vez verificada la actuación administrativa se deja constancia de su correcta o incorrecta realización; y una segunda, extensiva, que incluye, además de la verificación, la imposición de un resultado al ente administrativo controlado, el que los autores consideran que es un medio de prueba como documento público para exigir la responsabilidad del controlado. En el ámbito de fiscalización de la actuación administrativa,elinteréspúblicoseimpone como un elemento de comprobación de su actividad que entronca en todo su quehacer y, a la par, contribuye con la materialización de otro de los principios que orientan el actuar administrativo: el de responsabilidad. Como afirmara Dromi, "el control se impone como deber irreversible, irrenunciable e intransferible para asegurar la legalidad de la actividad estatal". ${ }^{32}$

La actividad de control se configura como un principio en relación con la Administración Pública, correlativo a las garantías que del principio de legalidad se derivan para el administrado. En virtud del principio de control, toda la actividad de la Administración debe estar sometida a mecanismos que permitan comprobar su actuación en relación con las normas y los principios jurídicos que la orientan. En este marco, un órgano -de igual función o diferente, jerárquico o no-, verifica la actuación de la Administración, en relación tanto a su legitimidad como al fin previsto, con la posibilidad de aplicación de una medida de corrección de la situación controlada. El principio de control precisa concretarse mediante la creación de mecanismos, vías para su

32 DROMI, Roberto, El procedimiento administrativo, Ediciones ciudad Argentina, Buenos Aires, 1996, p.26. ejercicio, tema que alcanza con particular interés a los supuestos de ejercicio de la potestad discrecional.

Su resultado final como acto administrati$\mathrm{vo}^{33}$, culmina con la entrega de sus resultados finales a través de un instrumento público -informe resultados de la auditoría-, el que constituye en sede judicial un medio de prueba como ya hemos reseñado, ante la exigencia de la responsabilidad en la vía jurisdiccional o la administrativa, y para aplicar dentro del sujeto auditado todas las acciones correctivas que resulten necesarias para dar respuestas a los señalamientos realizados en todas las etapas del control a través de la auditoría -proceso-, al ser aplicados los procedimientos -guías y metodologías-.

La auditoría, concebida como un proceso, a partir de su génesis latina, donde se define como acta judicialitía, lis, litis, actio, causa, y judicium, en si proceso está concebido como la acción de ir hacia delante. Es la sucesión de diferentes fases o etapas de un fenómeno o actividad, y el conjunto de acciones sucesivas realizadas con la intención de obtener un resultado. Desde las ciencias jurídicas, proceso es un conjunto de actos complejos de las partes y de los terceros, que tienden a la aplicación de una ley general o a un caso concreto para solucionarlo o dirimirlo. Como procedimiento la auditoría, a partir de su etimología, apreciamos que se le reconoce como procesio, en el ámbito jurídico se le reconoce como judiciorum formulae, lo que significa método de ejecutar algunas cosas, manera de proceder, o actuación de trámites judiciales o administrativos, en fin es la acción de proceder. En el control administrativo se le conoce como el conjunto de normas y trámites seguidos en la actuación gubernativa. Dromi, señalaba

33 GORDILLO, A. 2006. Tratado de Derecho Administrativo. Argentina. Ediciones Macchi. 
en este aspecto, que el procedimiento administrativo es un instrumento de control y de gobierno. ${ }^{34}$

Así las cosas, constatamos que el control y la fiscalización son encargadas al órgano de control administrativo, es el uso de medios jurídicos para anular, rectificar o sancionar la gestión pública ilegal o ineficaz, lo hace a través de medios técnicos con la denominación de procedimientos administrativos, los que se ejecutan a través de la auditoría para determinar la juridicidad de los actos de las autoridades administrativas, con un carácter instrumental. Reconocer el control, como principio, significa extenderlo a todas sus formas y manifestaciones y extenderlo a la variedad de actuaciones en que se desenvuelve la Administración Pública.

$\mathrm{Su}$ asidero jurídico se aprecia a partir de su reconocimiento en los textos constitucionales de América Latina, ejecutada a través de los Tribunales de Cuentas, Contralorías y Oficinas de Auditorías como los órganos ejecutantes. Esto deriva un desarrollo normativo que regula la función orgánica de este órgano de control, su competencia, jurisdicción, ello se aprecia por los autores a partir de su reconocimiento en Leyes de la Contraloría, de Auditoría Pública, de Responsabilidades de los Servidores Públicos, y en la de Procedimiento Administrativo, desde su vertiente jurídica de la Responsabilidad, al controlar para responsabilizar a los sujetos auditados, al decir de Lara Ponte, Cossío Díaz, Luciano Parejo. ${ }^{35}$

\footnotetext{
34 DROMI, Ibídem p.26 y ss.

35 LARA PONTE, Rodolfo, Naturaleza jurídica administrativa de los Órganos de Control, perspectivas actuales del Derecho, ITAM, 2010; COSSÍO DÍAZ, Ramón, El Derecho y el combate a la corrupción, Boletín Asofis, número 22, 2001, México, p.107; LUCIANO PAREJO, Alfonso, Manual de Derecho Administrativo, volumen I, Editorial Ariel, Barcelona, 1989, p.240 y ss.
}

Es entonces, que la Auditoría Gubernamental, es concebida como la herramienta por excelencia para el autocontrol, se conceptualiza como:

\section{(...) la función contable de la verificación} de los actos administrativos, en cuanto puedan afectar al patrimonio y ser objeto de registro. Es una especialización dentro de la Ciencia Contable, delimita su campo de acción y previene contra la tendencia de hacerla aparecer con caracteres diferentes de la contabilidad. No existen dudas de su importancia como elemento en el control, su misión concluye con la entrega de los resultados del control, la puntualización de los errores, defectos, delitos comprobados, pero las medidas correctivas le competen a otras especialidades contables o legales (.... ${ }^{36}$

Para los autores el control es un acto de poder para ejecutar su control, ya Valadés ${ }^{37}$ señalaba que controlar el poder es un acto de poder, toda vez que el control del poder tiene un doble objeto: la defensa de las libertades y la preservación de la legitimidad. El control no se ejerce para destruir ni sustituir al poder, se ejercer por el propio poder para su mantenimiento.

Nava Negrete, estimó que los principios de autolimitación, legitimidad y control son partes orgánicas que estructuran al Estado de Derecho, ubican el origen del control en la desconfianza y en la probabilidad de que la Administración ponga sus actos fuera de la Ley. Esto se expresa en que el Estado de Derecho, tiene la obligación de que los procesos de control se instrumenten en normas jurídicas y procesos específicos, que permitan detectar y combatir los problemas del servidor público deshonesto, ante actos como el soborno, la

36 ENCICLOPEDIA OMEBA de contabilidad, Biblioteca de Contabilidad, Argentina, 1984.

37 VALÁDES RÍOS, op cit p.6 
corrupción, el fraude, y la malversación, y otras actitudes antijurídicas. ${ }^{38}$

Martínez, por su parte considera que el poder jurídico del control es un poderdeber, al ser su ejercicio obligatorio, integrado a la función estatal de contenido jurídico. Con relevancia en el Estado de Derecho. Este se impone para asegurar la sujeción del obrar público a reglas y principios del Derecho y de la buena administración, para verificar la correspondencia entre medios y fines. ${ }^{39}$

\section{EL CONTROL PÚBLICO EN CUBA}

La Intosai, Organización Internacional de las Entidades Fiscalizadoras Superiores, al agrupar a las instituciones de fiscalización (auditoría o control) de los países miembros, es un organismo autónomo, independiente y apolítico, siendo uno de sus principales objetivos el de prescribir recomendaciones y líneas de acción que promueven fomentar y garantizar la independencia y profesionalidad en el ejercicio de la auditoria gubernamental externa. Ejerce funciones de investigación especializada y sirve como centro de información, enseñanza, coordinación y asesoría mutua entre entidades fiscalizadoras. Brinda un marco institucional para generar $\mathrm{y}$ transferir conocimientos que mejoren a nivel mundial la fiscalización pública exterior y que contribuyan a fortalecer la posición, competencia y prestigio de las distintas EFS en sus respectivos países. Cuba como nación es parte de la organización regional de América Latina y el Caribe denominada OLACEFS.

La finalidad de la auditoría por sus ejecutantes de las EFS es mantener, controlar y evaluar la efectividad del

38 NAVA NEGRETE, Alfonso, Derecho Procesal Administrativo, Editorial Porrúa, México, 1967.

39 MARTÍNEZ, p.184 sistema en las instancias de dirección, señalado por autores de la talla de Gordillo, DromiyMuñozMachado ${ }^{40}$.Suimportancia radica en la comprobación de las políticas del Estado en la preservación de las finanzas públicas y el control económico administrativo, incorporándosele la dimensión ambiental en la década de los 90 del pasado siglo XX, ponderada en el siglo XXI ante las consecuencias negativas generadas por la corrupción, el cambio climático, contextualizadas con la implementación de la Responsabilidad Social Empresarial ${ }^{41}$.

En la práctica de auditoría existe un documento, tanto en el entorno privado como público denominado -Informe Coso-, sibien nacidodesdey parael sector privado, establece una serie de pautas generales de funcionamiento sistémico, que puede adaptarse a la actividad gubernamental. El concepto de control, determina que un sistema de control está conformado por cinco componentes relacionados entre sí e integrados en el proceso de dirección de la organización. Estos componentes son: entorno de control, evaluación de riesgos, actividades de control, información y comunicación y supervisión. Por su parte, se establece que el objetivo organizacional está conformado por la realización de operaciones en forma eficiente y eficaz, la generación de información financiera confiable y el cumplimiento de la normativa y leyes en el que se encuentra la actividad organizacional, a partir de la teoría de Cooper\&Librand. ${ }^{42}$

40 GORDILLO, Agustín, Tratado de Derecho Administrativo, $8^{\text {va }}$ edición, Editorial Macchi, Argentina, 2006; DROMI, Roberto, El procedimiento administrativo, Editorial Ciudad Argentina, Buenos Aires, 1996; MUÑOZ MACHADO, Manuel, Tratado de Derecho Administrativo y Derecho Público General, Editorial Iustel, España, 2011.

41 Libro Verde. Unión Europea. Bruselas. 2001; ISO 26000:

42 COOPERS \& LYBRAND, Los nuevos conceptos de control interno, tomo I, Editorial Días de Santos, España, 1997. 
Esta actividad de control administrativo -auditoría- por ser una de las actividades más importantes que ejercita la Administración Pública como Estado vigilante, sus destinatarios son las formas de gestión sujetas a acciones de control por la norma legal que la regule, están obligados a mantener sistemas de control interno conforme a sus características, competencias y atribuciones. Su finalidad preventiva va dirigida a constatar la juridicidad del sujeto auditado, al ser solicitada por el mismo de manera voluntaria, al decir de autores como Esteve Pardo, Sanz Rubials, y Sanz Larruga. ${ }^{43}$

De igual forma, la práctica de la auditoría, como actividad de control administrativo y como herramienta técnica, utiliza mecanismos para comprobar la juridicidad del sujeto auditado, de amplia aplicación por parte de las EFS al reconocerse ambas denominaciones para su ejecución por los auditores, su evolución se materializa en correspondencia a las áreas geográficas donde se aplica, y al nivel de desarrollo tecnológico de la industria, de aquí que se constate el cambio de escenario en América Latina del control a las industrias hacia la naturaleza, referido por autores como Caferrata, De Besa Antunes, Bellorio Clabot, Lorenzetti, Martin Mateo, y Antúnez Sánchez. ${ }^{44}$

43 ESTEVE PARDO, José, Lecciones de Derecho Administrativo, Editorial Marcial Pons, España, 2011, pp.3-27, SANZ RUBIALS, Iñigo, Derecho Administrativo Sancionador, Editorial Lex Nova, España, 2010; SANZ LARRUGA, Francisco, Sostenibilidad ambiental y Derecho Administrativo: ¿nuevo remedio ante la crisis económica ouna exigencia constitucional? A propósito de la nueva Ley de Economía Sostenible, VI Congreso de la Asociación de profesores de Derecho Administrativo, Palma de Mallorca, 2011.

44 CAFERRATA, Néstor Alfredo, Derecho Ambiental Latinoamericano, VII Jornadas Internacionales sobre Medio Ambiente, Salta, 2013; DE BESA ANTUNES, Paulo, Direito Ambiental, Editorial Lumen Juris, Brasil, 2010; BELLORIO CLABOT, Dino, Tratado de Derecho Ambiental, tomo III, $1^{\text {ra }}$ edición, Editorial Astrea, Buenos Aires, 2004; LORENZETTI, Ricardo Luis, Teoría del Derecho Ambiental, $1^{\text {ra }}$ edición, Editorial Porrúa, México, 2008; MARTÍN MATEO, Ramón, Derecho
La Asociación Americana de Contabilidad, define a la auditoría como:

(...) proceso sistemático para obtener y evaluar de manera objetiva las evidencias relacionadas con informes sobre actividades económicas y otros hechos relacionados. Su finalidad consiste en determinar el grado de correspondencia del contenido informativo con las evidencias que le dieron origen, para determinar sí en dichos informes se han elaborado observando los principios establecidos para el caso (...) ${ }^{45}$

Desde las ciencias jurídicas, se constata la evidencia de pocos estudios sobre el tema del control administrativo ejecutado por la EFS en la nación cubana, resaltan los realizados en el siglo XX por Garcini Guerra, los realizados por Arias Gayoso, Matilla Correa y Antúnez Sánchez en el XXI; pero otros son los resultados desde los saberes contables e históricos, estos han ido señalando que el ejercicio de la auditoría pública como función estatal estuvo dedicada a controlar los bienes públicos en la nación desde sus comienzos.

Administrativo Ambiental, $6^{\text {ta }}$ edición, Editorial Trivium, España, 1997, ANTÚNEZ SÁNCHEZ, Alcides, Disquisiciones teóricas, doctrinales y exegéticas sobre la praxis de la auditoría como función pública, dirigida a la protección del bien público ambiental para la empresa ecológica, Revista Dos Tribunais Thomson Reuters, número 951, Brasil, 2015.

45GARCINI GUERRA, Héctor, Derecho Administrativo, Editorial Pueblo y Educación, $2^{\text {da }}$ edición, La Habana, 1986, pp.135-138; ARIAS GAYOSO, Grethel, Del nuevo Derecho Administrativo: Participación y control popular en la gestión pública. Participación Política, reflexiones desde el Sur, tomo II, $1^{\text {ra }}$ edición, Editorial Advantlogic, Ecuador, 2014; MATILLA CORREA, Andry (coord.) Panorama de la Ciencia del Derecho en Cuba, Estudios en homenaje al profesor Dr. Julio Fernández Bulté, Lleonard Muntanar, Palma de Mallorca, 2009; ANTÚNEZ SÁNCHEZ, Alcides Francisco, La auditoría ambiental practicada por la Contraloría General de la República de Cuba. Las formas de actividad administrativa en la actualización del modelo económico cubano para el futuro ordenamiento jurídico en el desarrollo del Derecho Ambiental patrio, Revista Temas SocioJurídicos, número 68, Bucaramanga, 2015. 
Un primer análisis o acercamiento en el control público constata que Cuba por ser una de las colonias de España, la economía era regida y controlada por la metrópoli al ser esta la dueña de los negocios de forma mayoritaria que florecían en esta época los sujetos privados. Las evidencias refieren que los cubanos de este período analizado no ejecutaron la auditoría ni tenían los conocimientos requeridos para ello, la misma era realizada por inspectores para controlar los negocios propiedad de los españoles, reseñados por los estudios desde los saberes contables por autores como Pozos Ceballos y Villardefrancos Álvarez. ${ }^{46}$

El período comprendido a partir del siglo XVII hasta el XVIII, evidenció que esta función de control por la Administración a las finanzas públicas fueron ejecutadas por la Intendencia de Hacienda y el Tribunal de Cuentas en 1764, ambas instituciones ejecutaron las funciones de percepción de los registros contables, la vigilancia de las rentas y de los recursos públicos, tuvieron su asidero legal en la Constitución de 1940, en su artículo 266. A partir de entonces sobre estos dos órganos recayeron las funciones del conocimiento y vigilancia de los registros contables relacionados con las rentas y recursos públicos.

Posteriormente los organismos de control continuaron perfeccionándose con la introducción de mecanismos para hacer más eficientes y eficaces la salvaguarda

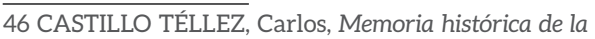
actividad de la auditoría pública en la República de Cuba, Archivo de la Contraloría General de la República de Cuba, La Habana, 2014; POZO CEBALLOS, Sergio, Naturaleza y papel de la Contraloría General de la República de Cuba dentro del Sistema de Control Externo, Revista electrónica de contabilidad y finanzas COFIN Habana, La Habana, 2011, Disponible en hptt:// www. cofinhab.uh.cu/; VILLARDEFRANCOS ÁLVAREZ, María, La auditoría como proceso de control: concepto y tipología, Revista Ciencias de la Información, volumen 37, Número 2, Cuba, 2006. de la Hacienda Pública, acorde a los intereses de la colonia española. La historia económica del país, reconoce las tendencias que hubo sobre la formación y la constitución de los organismos técnico-económicos, como los factores que dieron lugar a la creación del Consejo de la Administración donde participaba el Intendente General de Hacienda y el Presidente del Tribunal de Cuentas, fortaleciéndose los mecanismos de control. Entre 1790 y 1837 se constituyen en Cuba los organismos técnico-económicos, dando lugar en 1861 a la creación del Consejo de la Administración, en el que participaban el Intendente General de Haciendas y el Presidente del Tribunal de Cuentas. Este fue sin dudas uno de los pasos más importantes para la época en función de fortalecer los mecanismos de control de la Administración Pública.

Para el siglo XIX, se corrobora la promulgación del Decreto No. 78 Ley del Poder Ejecutivo, como la normativa organizadora de las funciones de fiscalización ejercitadas por el Interventor General de la República en esta etapa. Hacia 1909 con la neocolonia, se establece que la actividad de fiscalización ejecutada por el Interventor General de la República, nombrado por el Presidente y subordinado al Ministerio de Haciendas. La función era examinar las cuentas del Estado y certificar sus saldos. Evidentemente la función era básicamente contable.

Siguiendo este mismo íter, se aprecia que en la Constitución de la República de 1940 se reguló la función de fiscalización a los bienes públicos por parte del Ministerio de Hacienda, institución creada por la Ley Orgánica del Poder Ejecutivo. Conforme con la Constitución, la creación del Tribunal de Cuentas tuvo entre sus funciones la de fiscalizar el patrimonio, los ingresos, 
los gastos del Estado y a los organismos autónomos para comprobarles la ejecución de sus presupuestos destinados por el Estado a las provincias y municipios, con la observancia de las leyes y las disposiciones en materia de impuestos, derechos y contribuciones en vigor con toda la autoridad administrativa de fiscalizar la gestión pública de los funcionarios y de los empleados del aparato estatal, como de las organizaciones autónomas en esta etapa.

El Tribunal de Cuentas, institución con carácter autónomo y jurisdicción más amplia, fue creado oficialmente en 1950, tenía entre sus funciones supervisar el patrimonio, ingresos y gastos del Estado y de los organismos autónomos, además se encargaba de la ejecución del presupuesto estatal, y asegurar el cumplimiento de las leyes y normativas relativas a impuestos, contribuciones, y funciones afines, este cesó en sus funciones en 1960. Tal y como se reconoce en los estudios realizados desde los saberes históricos por Portuondo del Prado y Torres Cuevas. ${ }^{47}$

\section{$2.1 \mathrm{El}$ proceso revolucionario y la Nacionalización}

A partir del triunfo de la Revolución se inicia todo un cambio en la estructura socio-económica del país, proceso este que provocó una acelerada transformación dentro de la organización del aparato estatal y con ello de la contabilidad, la auditoría y el control de los hechos económicos en el sector estatal dentro de sus formas de gestión a partir de los cambios acontecidos a nivel mundial en los objetivos de la actividad de control analizada, la que solo se dedicó en sus

47 PORTUONDO DEL PRADO, F.1965. Historia de Cuba 1492-1898. La Habana. Ediciones Instituto Cubano del Libro; TORRES CUEVAS, E. 2007. 1492-1898. Historia de Cuba, formación y liberación de la nación. La Habana. Ediciones Félix Varela. orígenes a la detección de fraudes, a la revisión de los sistemas y a la obtención de evidencias, se valora como se ha extendido de manera progresiva al control ambiental ante los altos índices de contaminación generados por las industrias en sus procesos productivos y de los servicios. Evidencias analizadas confirman que la actividad de control y fiscalización prosiguió en evolución a través de las funciones realizadas por el Tribunal de Cuentas y el Ministerio de Hacienda con un mismo objetivo, controlar los bienes públicos en la nación.

El gobierno decide en este momento implementar otros mecanismos para salvaguardar los intereses del pueblo, para ello se constituyó el Ministerio de Recuperación de Bienes Malversados dentro de la Administración Pública, como continuador de la función pública estudiada en 1959. La estructura y funciones de las estructuras que ejercerían el control en el país se amoldaron al nuevo Gobierno Revolucionario y a las necesidades de su pueblo.

La primera transformación en este orden fue el 13 de febrero de 1959, cuando el gobierno revolucionario dicta la Ley No. 78, Ley Orgánica del Ministerio de Recuperación de Bienes Malversados, en su contenido medular se expresaba:

(...) Es el organismo idóneo del Poder Ejecutivo destinado a recuperar los bienes de cualquier clase sustraído al patrimonio Nacional y lograr el reintegro total del producto de los enriquecimientos ilícitos obtenidos. Se entenderá integrado el Patrimonio Nacional por el Patrimonio del Estado, de las Provincias, de los Municipios, de los Organismos Autónomos y Paraestatales y de las Cajas de Retiros y de Seguros Sociales. La acción del Ministerio 
comprende a los funcionarios y empleados públicos y organismos y corporaciones autónomas y los relacionados en el artículo 154 de la Ley Orgánica del Tribunal de Cuentas (...)

Ley que estuvo encaminada a la eliminación de la corrupción política y administrativa, dio un golpe mortal a la malversación de los fondos públicos, a las denominadas "botellas" y castigó a quienes se habían enriquecido a costa del sudor y la miseria de los trabajadores, al decir de Cantón Navarro y Duarte Hurtado en sus estudios sobre historia de Cuba. ${ }^{48}$

Se resuelve a raíz de los cambios y modificaciones en la estructura económica del país, no mantener la labor que venía ejerciéndose por el Tribunal de Cuentas en la función del control público, órgano que cesa en sus funciones en 1960. Para 1961, se decide la constitución del Ministerio de Hacienda con la Ley No. 943 como su sustento legal, organismo al que se le concedieron las funciones de comprobación de los gastos del Estado por parte de la Dirección de Comprobación, encargada de realizar la fiscalización en toda la nación. Al finalizar 1965, es disuelto este Ministerio de Hacienda, pasando las funciones de control al Banco Nacional de Cuba con la Dirección de Comprobación antes citada, actividad que perduró hasta 1967, este control público tuvo su asidero jurídico en la Ley fundamental de 1959.

Así las cosas, esta actividad de control practicada en el período revolucionario se decidió que fuera ejecutada por otro organismo del entramado administrativo, le correspondió al Ministerio de Industrias, el fundamento legislativo se

48 CANTÓN NAVARRO, J. y DUARTE HURTADO, M. Cuba 42 años de Revolución. Cronología histórica 1959-1982, tomo I, Editorial de Ciencias Sociales, La Habana, 2006. mantuvo regulado en la Ley fundamental de 1959. En esta etapa se tomó la decisión de conformar las primeras Unidades de Auditoría Interna en todos los organismos de la Administración Pública, constatándose con ello los principios del Derecho Administrativo de centralización y descentralización para el control administrativo, dirigido en esencia a las finanzas públicas del sector estatal, al ser este el sector preponderante en los sujetos económicos dentro del tráfico mercantil del sector estatal. Tal y como se cita en las memorias del órgano de control por Castillo Téllez. ${ }^{49}$

\subsection{La Oficina Nacional de Auditoría}

Para 1976, período de institucionalización estatal, sustentado en la Ley No. 1323, se constituyó el Comité Estatal de Finanzas para el control a los bienes públicos con la Dirección de Comprobación dentro de la Administración Pública, este organismo tuvo en sus funciones básicas la práctica de la auditoría estatal por parte del Estado como el ente superior, continuando las actividades que venía ejecutando el Ministerio de Industrias. Actividad que estuvo sustentada a partir de lo establecido en el texto constitucional cubano, en su artículo 10 y cito:

(...) todos los órganos del Estado, sus dirigentes, funcionarios y empleados, actúan dentro de los límites de sus respectivas competencias y tienen la obligación de observar estrictamente la legalidad socialista y velar por su respeto en la vida de toda la sociedad (...)

La función de control, ejecutada por el Comité Estatal de Finanzas confirma que

49 CASTILLO TÉLLEZ, C. 2014. Memoria histórica de la Oficina Nacional de Auditoría y del Ministerio de Auditoría y Control. La Habana. Contraloría General de la República. 
la práctica de esta función pública, concebida por el Derecho Administrativo como una actividad de control, realizada a los organismos que integran la Administración Pública de forma obligatoria para el control de las finanzas públicas, como característica en el ordenamiento jurídico patrio, la misma aparece regulada a partir del texto constitucional en su artículo 10, y en las normas sustantivas en los Decretos Leyes No. 67 de 1983 y el 147 de 1994, al ser mayoría los sujetos de gestión del sector estatal, para evaluar el principio de juricidad.

Así las cosas, la década de los 80 del pasado siglo, mostró sucesos internacionales y nacionales con repercusión en la auditoría estatal y en las acciones de control practicadas en la Administración Pública vinculadas con la caída del sistema socialista y de la Unión Soviética como el principal socio comercial con Cuba, elementos que obligaron al Estado a buscar otras relaciones a través de asociaciones económicas. Culminaron con el desarrollo de la inversión extranjera, y para ello son autorizadas en la nación firmas de auditoría privadas de otros países quienes de conjunto con auditores cubanos ejecutaron auditorías en el sector turístico de capital mixto fomentado en esta etapa.

La modificación del escenario internacional en la década de los 90 situó al país en una posición desventajosa ante las afectaciones directas como el parcial aislamiento internacional, la necesidad de reinsertar las relaciones económicas en un mundo unipolar y la intensificación del bloqueo económico por los Estados Unidos de América. Con la evolución de la auditoría en las formas de gestión del sector estatal cubano a partir de 1994 se continua la decisión de perfeccionar el trabajo de la Administración Estatal, se decide para ello concluir las funciones que realizaba el Comité Estatal de Finanzas y Precios, trasladadas al Ministerio de Finanzas y Precios (MFP). En este nuevo organismo se conformó la Oficina Nacional de Auditoría (ONA) la que funcionó dentro de los órganos locales del Poder Popular de todo el país, tal y como referíamos con anterioridad al aplicarse la desconcentración administrativa para su ejecución al sector estatal.

Las normativas jurídicas en relación con la auditoría pública tuvieron sustento legal en el Decreto Ley No. 159 de 1995, normativa reguladora de los deberes y derechos de los auditores y de los auditados como los sujetos activos de esta relación jurídica administrativa como función estatal y para los que la practican de forma autónoma. Complementada por el Acuerdo No. 2819 del Comité Ejecutivo del Consejo de Ministros de 1995 y por el Decreto No. 228 de 1997 para aplicar las contravenciones personales en materia de auditoría al exigirse la responsabilidad administrativa.

La ONA, tuvo como objetivos fundamentales organizar y dirigir toda la actividad de control en la nación, para ello estableció principios, normas y procederes para ejecutar el control público a las personas naturales o jurídicas que recibieran recursos financieros entregados por el Estado. Esta función pública propició el desarrollo de otras tipologías de auditorías como la de gestión, la financiera y la especial, realizadas en objetivos económicos dentro o fuera del territorio nacional de forma obligatoria con arreglo a un plan.

Le correspondió a la ONA evaluar los sistemas contables en las entidades auditadas para determinar el grado de 
control y confiabilidad al certificarles su contabilidad, a su vez, organizó y dirigió el orden metodológico de la auditoría estatal como procedimiento en la ejecución de este control administrativo, controló el trabajo de las Unidades de Auditoría Interna y la asesoría periódica al ejercitar la supervisión a las Unidades Centrales de Auditoría de los organismos de la Administración Pública y en los órganos locales del Poder Popular, manteniéndose la centralización y la descentralización de esta función pública en todo el país.

Todo el desarrollo de la auditoría dentro del MFP permitió confeccionar el plan de auditorías del Estado cada año, elaborar los programas y las guías metodológicas -procedimiento- al amparo del Decreto Ley No. 159 de 1995 para fortalecer el control económico en el sector estatal cubano. Fue creado el Registro de Auditores para el proceso de habilitación y registro de los profesionales practicantes de la auditoría pública y la privada.

En la aplicación del Decreto Ley No. 159 de 1995 por los servidores públicos, se valoró en el plano jurídico la declaración del Estado de fortalecer el control económico y administrativo de las formas de gestión estatal dirigidas a prevenir el uso indebido de los recursos, la disciplina y la responsabilidad, que permitieran demostrar la transparencia en la información económico-contable a los niveles superiores de la Administración, verificar la honestidad de las personas naturales y jurídicas en la administración de los recursos estatales como servidores públicos; factores estos que permitieron un mayor nivel de independencia y autonomía de la función pública, regulada en manuales y procedimientos administrativos internos por la ONA en este etapa.
Se aprecia que desde 1985 hasta 1993, el Estado realizó nuevos estudios vinculados a la actividad de la auditoría para fortalecer los mecanismos de control y crear un órgano de fiscalización superior en la nación que ejecutara el control gubernamental con la participación de los organismos rectores de actividades de interés estatal en materia económica y en las funciones de la Comisión de Control Gubernamental formada por el Estado, para pasar a otro nivel en el control público del país.

Entre los años 1999 al 2000, se corrobora la continuidad de otros estudios para consumar la propuesta de crear un órgano soberano en base a la experiencia alcanzada en América Latina y en la Unión Europea, que permitieran cumplir con efectividad las políticas públicas vinculadas a la actividad de control analizada y se adaptara a las características de Cuba, a las nuevas concepciones de la INTOSAI y a los hechos internacionales con repercusión en la actividad de la auditoría pública, toda vez que la dialéctica y el desarrollo de la auditoría reclamaban un organismo superior en el país, como fuera señalado por Antúnez Sánchez en sus resultados investigativos. ${ }^{50}$

\subsection{El Ministerio de Auditoría y Control}

Es entonces que se toma la decisión por el Estado crear el Ministerio de Auditoría y Control (MAC) dentro de los organismos de la Administración Pública como funcionó la ONA, solo que ya no dentro de un Ministerio como su antecesora lo fue, este fue el sujeto activo que realizó la actividad de control y la fiscalización

50 ANTÚNEZ SÁNCHEZ, Alcides, La auditoría ambiental: Una revisión y propuestas en clave de su función pública y dimensión empresarial, Revista Iberoamericana de Contabilidad de Gestión, número 26, España, 2015, pp.3-27 
gubernamental, ejercitó funciones revolucionarias, modernas, de elevados valores, para el control adecuado de la eficiencia de la economía y la probidad de los funcionarios y directivos del país en una tercera etapa del control público. Las funciones de la actividad de auditoría atribuidas a la ONA y al Ministro de Finanzas, excepto la contenida en el artículo 33 del Decreto-Ley No. 159 de 1995 fueron asumidas por el MAC, a partir de la entrada en vigor del Decreto-Ley No. 219 de 2001 y qué como expresión jurídica se manifestó en las materias de auditoría, el control gubernamental y la fiscalización que tuvo dentro de su encargo público.

Alarcón de Quesada, como Presidente de la Asamblea Nacional expresó y cito:

\section{(...) en el caso cubano la Asamblea Nacional} y la dirección del gobierno consideraron positiva la gestión del MAC, como órgano principal del Estado para la fiscalización y el control, en la detección de ilegalidades, actos de corrupción administrativa y confabulación para delinquir, hechos que en ocasiones se presentaron en empresas de propiedad estatal, y en su gran mayoría en funcionarios de los niveles intermedios (...) ${ }^{51}$

Se justiprecia que la creación del MAC en la Administración Pública, como sujeto activo encargado de dirigir, ejecutar y controlar la aplicación de la política estatal y de gobierno en las materias de auditoría gubernamental, fiscalización y control gubernamental para regular, organizar, dirigir y controlar a través de metodologías todo el Sistema Nacional de Auditoría revolucionó la auditoría como actividad de control administrativo a las formas de gestión del sector estatal en el sentido de

51 ALARCÓN DE QUESADA, Ricardo, Informe reunión OLACEFS celebrada en la ciudad de La Habana, Revista Ministerio de Auditoría y Control, La Habana, 2003. su ejercicio práctico, al ser estos sujetos de gestión los de mayor representatividad en la nación.

Al MAC en su actividad de control administrativo a los bienes públicos le diferenciaron de las acciones realizadas por la ONA, ante los nuevos conceptos incorporados a través de la auditoría gubernamental, como la auditoría externa realizada por el gobierno central a los órganos y organismos de la administración central del Estado, a las instituciones financieras bancarias y no bancarias y a las organizaciones económicas estatales, a las entidades del sector cooperativo, organizaciones, asociaciones, asociaciones internacionales y demás entidades económicas cuando reciban por disposiciones gubernamentales subsidios, subvenciones, ventajas, exenciones y concesiones, o presten un servicio público o establezcan contratos o compromisos con el gobierno o con entidades estatales y a cualquier persona natural o jurídica que realice actividades lucrativas sujetas a obligaciones tributarias.

Con la función de fiscalización, comoel acto de verificación, inspección, investigación y comprobación realizada a los órganos y organismos de la administración central del Estado, por las organizaciones económicas estatales y a los dirigentes y funcionarios designados o aprobados por la autoridad u órgano del gobierno con la finalidad de velar por el cumplimiento de las disposiciones estatales y del gobierno vinculadas con la actividad económico financiera para preservar la disciplina y la integridad administrativa, prevenir y detectar los actos de corrupción administrativa, ejecutada de conformidad con los planes anuales sobre la base de intereses estatales y por las quejas $y$ denuncias de la ciudadanía vinculada a 
las ilegalidades en el control y el uso de los recursos del Estado y a los actos de corrupción administrativa.

Con el control gubernamental, verificación realizada por las comisiones de trabajo que se constituyen con la participación de organismos de la Administración Central del Estado para aplicar las políticas de gobierno y el cumplimiento del plan y del presupuesto por los organismos de la Administración del Estado y las entidades de su sistema, ejecutada acorde a un plan anual conformado por el Consejo de Ministros.

Se justiprecia que en función de los tres principios básicos del MAC dentro de los organismos de la Administración Pública en el país con las funciones de prevención, detección y enfrentamiento a los actos de corrupción administrativa, lo diferencian de la actividad de control que se realizaba en Cuba con la práctica de la auditoría estatal como actividad de control que practicó la ONA, los que fueron realizados a través de la función inspectiva y la auditoría, como se reseñara por Antúnez Sánchez y Ramírez Sánchez. ${ }^{52}$

Desde el punto de vista jurídico, los autores valoran que la práctica de la auditoría ejercitada por la ONA y el MAC como EFS continuó dirigida en esencia a la revisión de los sistemas contables a las formas de gestión del sector estatal por ser este mayoritario en el escenario mercantil, prueban que la actividad de control administrativo analizada, la normativa que regula la auditoría en el ordenamiento jurídico patrio se caracteriza por ser obligatoria, gratuita,

52 ANTUNEZ SANCHEZ, A.; RAMIREZ SANCHEZ. A. La potestad inspectiva $\mathrm{V} / \mathrm{s}$ la auditoría pública. Ojeada histórica dentro del derecho administrativo ambiental cubano. ejecutada en un plan auditor, realizada a partir de programas y metodologías; en la nación ha sido realizada por la EFS al tener su titularidad y por las sociedades mercantiles concesionadas para su ejercicio con auditores habilitados para ejercer esta función pública, percibiéndose la gestión directa y la indirecta. Pero sin un adecuado constructo doctrinal desde el Derecho Administrativo cubano como se ha venido señalando en las investigaciones de Antúnez Sánchez, al ponderarse solamente lo señalado por Garcini Guerra en relación al control y la fiscalización en su obra académica en el pasado siglo $X X{ }^{53}$

\section{LA CONTRALORÍA GENERAL DE LA REPÚBLICA}

A partir de lo que se señala en la Constitución de la República estipula:

(...) el Estado administra directamente los bienes que integran la propiedad socialista de todo el pueblo; o podrá crear y organizar empresas y entidades encargadas de su administración, cuya estructura, atribuciones, funciones y el régimen de sus relaciones, son regulados por la ley"...,) (..."Estas empresas y entidades responden de sus obligaciones sólo con sus recursos financieros, dentro de las limitaciones establecidas por la ley. El Estado no responde de las obligaciones contraídas por las empresas, entidades u otras personas jurídicas y éstas tampoco responden de las de aquel (...)

Lo establecido en el texto constitucional, ha permitido conocer en el plano jurídico cómo a través de la normativa sustantiva

53 GARCINI GUERRA, Ibídem p.11; ANTÚNEZ SÁNCHEZ, Alcides, Disquisiciones teóricas, doctrinales y exegéticas sobre la praxis de la auditoría como función pública, dirigida a la protección del bien público ambiental para la empresa ecológica, Revista Dos Tribunais Thomson Reuters, número 951, Brasil, 2015. 
se aplican las herramientas e instrumentos relacionados con la actividad de control estudiada, que permitan observar los impactos generados en relación a los estados financieros $\mathrm{y} / \mathrm{o}$ presupuestos vinculados a los aspectos económicosfinancieros en las formas de gestión del sector estatal cubano.

Para ello, con el proceso de actualización y reforma del modelo económico, los estudios realizados sobre la auditoría a partir de la primera década del siglo XXI permitieron conocer la nueva decisión a nivel de Estado para crear la Contraloría General de la República (CGR) en Cuba, como el nuevo órgano de control supremo, sustentado en la Ley No. 107 de 2009, considerada por Antúnez Sánchez como la actual etapa del control público en la nación. ${ }^{54}$

Ahora bien, la conformación en Cuba de la CGR como Estado Socialista, permite reconocer que se está en un estadio superior del control público. Lo que ha motivado hacer un estudio desde los saberes históricos-jurídicos de su tracto a partir de la Historia de Cuba, de la Historia del Estado y el Derecho, del Derecho Constitucional, del Derecho Público, tal y como lo señalan autores como Portuondo del Prado, Cantón Navarro, Torres Cuevas y Pérez Bultés ${ }^{5}$ de como en cada período constatado en la nación se ha materializado

54 ANTÚNEZ SÁNCHEZ, Alcides, La auditoría ambiental: Una revisión y propuestas en clave de su función pública y dimensión empresarial, Revista Iberoamericana de Contabilidad de Gestión, número 26, España, 2015, pp.3-27

55 PORTUONDO DEL PRADO, Fernando, Historia de Cuba 1492-1898, Editorial Instituto Cubano del Libro, La Habana, 1965; CANTÓN NAVARRO, Julio, Historia de Cuba, tomos I-II, Editorial Ciencias Sociales, La Habana, 2009; TORRES CUEVAS, Eduardo, 1492-1898. Historia de Cuba, formación y liberación de la nación, Editorial Félix Varela, La Habana, 2007; FERNÁNDEZ BULTÉ, Julio, Historia del Estado y del Derecho, Editorial Félix Varela, La Habana, 2003. el control administrativo para evaluar las finanzas públicas.

Se corrobora como el país se insertaba en las novedosas tendencias internacionales declaradaspor lasEFS, siendoesteelórgano que auxiliará a la Asamblea Nacional y al Consejo de Estado en la ejecución de la más alta fiscalización sobre los órganos del Estado y del Gobierno, al ser continuador de las actividades que realizaron la ONA y el MAC en las etapas que le antecedieron. No obstante se valora, que la decisión que determinó la creación de la CGR en Cuba se diferencia de las etapas anteriores analizadas al control a los bienes públicos, está determinada por la firma del Estado cubano de la Convención internacional contra la corrupción y a los cambios de rendición de cuentas de esta actividad de control por la Administración Pública, a partir de que la Ley No. 107 de 2009, define a la auditoría como:

(...) proceso sistemático, realizado de conformidad con normas y procedimientos técnicos establecidos, consistente en obtener y evaluar objetivamente las evidencias sobre las afirmaciones contenidas en actos jurídicos o de carácter técnico, económico, administrativo u otros, con el fin de determinar el grado de correspondencia entre esas afirmaciones, las disposiciones legales vigentes y los criterios establecidos (...)

La CGR de Cuba al amparo de los artículos 9 y 75 constitucionales, como los fundamentos legales de su creación, señalan que le corresponde ejercitar el más alto control estatal a los sujetos de gestión de forma obligatoria, ya que está concebida la auditoría como una actividad de control, empero los autores consideran que lo normado entra en contradicción al no estar reconocida de manera adecuada en esta norma suprema de la nación el control administrativo al sujeto privado. 
Se valora que en sí la CGR no aparece reconocida como órgano de control dentro del texto constitucional cubano, lo que demuestra su antijuricidad al no estar legitimada su función pública en la ley de leyes de la nación, puede para ello apreciarse que el artículo 121 del texto constitucional, donde solo se reconocen con esta condición al Tribunal Supremoy el artículo 127 lo hace con la Fiscalía General de la República, órganos subordinados a la Asamblea Nacional y al Consejo de Estado, contrario a lo que concurre en América Latina y otros países donde se parte su legitimidad desde la norma suprema como ya hemos venido señalando.

Así las cosas, en la Ley No. 107 de 2009, se define en el artículo 11: la auditoría es un proceso sistemático, realizado de conformidad con normas y procedimientos técnicos establecidos, consistente en obtener y evaluar objetivamente las evidencias sobre las afirmaciones contenidas en actos jurídicos o de carácter técnico, económico, administrativo $\mathrm{u}$ otros, con el fin de determinar el grado de correspondencia entre esas afirmaciones, las disposiciones legales vigentes y los criterios establecidos.

La CGR en Cuba se subordina a la Asamblea Nacional y al Consejo de Estado, lo que demuestra un cambio en la rendición de cuentas y mantiene relaciones de coordinación, colaboración, supervisión y control con los organismos de la Administración Pública, al tiempo que puede auxiliarse de estos para el trazado de la política integral, apreciado cuando se ejecuta la evaluación del control interno y algunos tipos de auditorías de las que se establecen en el Reglamento de la Ley No. 107 de 2009. Como entidad al servicio del Estado y el Gobierno cubano, tiene la visión de ser: "un órgano que se distingue y caracteriza por sus valores éticos, alta profesionalidad y nivel de organización, capaz de influir en la creación de una cultura de responsabilidad, eficiente empleo de los fondos públicos y probidad administrativa, para prevenir y enfrentar indisciplinas, ilegalidades y manifestaciones de corrupción administrativa."

Los autores valoran que esta definición es afín con lo que señala la doctrina administrativa sobre el control, al ser este el conjunto de acciones que se ejecutan para comprobar la aplicación de las políticas del Estado, así como del cumplimiento del plan de la economía y su presupuesto, y la supervisión como el acto de inspección, investigación y comprobación que se realiza con la finalidad de velar por el cumplimiento de las disposiciones legales vinculadas con la actividad económicofinanciera, preservar la disciplina y la integridad administrativa, así como prevenir y detectar actos de corrupción administrativa; sobre la base de intereses estatales y a partir de las informaciones que se reciban por cualquier vía, en especial las provenientes del pueblo, vinculadas con la ilegalidad en el control y uso de los recursos del Estado y actos de corrupción administrativa, de aquí que se le reconozca dentro del control de la legalidad y de la gestión de los servidores públicos.

En la nación cubana se aprecia que los funcionarios como servidores públicos designados para ejercer esta función pública requieren de una habilitación oficial, esta se obtiene al realizar un examen en este órgano de control, lo que le permite lograr la inscripción en el Registro de Auditores al obtenerse la certificación que los acredita para esta potestad -técnicos, juristas y cientistas-. Este control público se práctica en todas las provincias de la nación a través de las Contralorías Provinciales al amparo 
de la Ley No. 107 de 2009. La CGR ejerce sus funciones y atribuciones en todo el país, así como en las sedes diplomáticas y en las representaciones y entidades en el extranjero del Estado cubano, ello permite ponderar a los autores la aplicación de los principios de descentralización y desconcentración.

Se aprecia también, todo el desarrollo normativo que ha tenido el control público a partir del Decreto Ley No. 159 de 1995, hasta la aprobación de la Ley No. 107 de 2009 y su Reglamento en el 2010 dentro del periodo revolucionario, la omisión del legislador al no derogarse el Decreto Ley No. 159 de 1995 en sus Disposiciones Finales, tal y como se hizo con el Decreto Ley No. 219 de 2001 en la Ley No. 107 de 2009. Se puede con ello demostrar que el ordenamiento jurídico patrio coexisten dos disposiciones jurídicas regulatorias del control a los bienes públicos, de la lectura de autores quienes desde la doctrina ponderan la técnica derogatoria en el proceso de creación de la norma jurídica como lo refieren autores como Hart, Aguiló, Fernández Bulté, toda vez que la normativa legal -Ley No. 107- no hay una derogación expresa que señale que la aludida normativa legal-Decreto Ley No. 159- quede sin efectos legales por parte del legislador, toda vez que pudiera entonces valorarse el criterio que su derogación sea considerada por los practicantes de esta actividad de control del órgano supremo nacional sea por desuso según la doctrina consultada. ${ }^{56}$

La propia Ley No. 107 de 2009, define los tipos de control administrativo a ejecutarse por la CGR, como son: el control integral,

56 HART, Herbert, Teoría del Derecho, Editorial Abeledo Perrot S.A., $2^{\text {da }}$ edición, Argentina, 1999, AGUILÓ REGLA, Joseph, Derogación, rechazo y sistema jurídico" en, Revista Informática y Derecho, Italia, 2000; FERNÁNDEZ BULTÉ, Julio, Teoría del Estado y el Derecho en Cuba, Editorial Félix Varela, La Habana, 2002. la inspección, y la comprobación especial. Empero, es destacable que en los años de constitución de la CGR ya se perciben resultados positivos a través de la función de control, la fiscalización a través de la ejecución de la función inspectiva, que permiten considerar que los sujetos económicos de la nación implementan el autocontrol dentro de sus formas de gestión, corroborados por los ejecutantes de la auditoría pública en todas sus tipologías, al ser esta más integral que la función inspectiva, tal y como lo reseñan autores de la talla de Esteve Pardo, Sánchez Morón, García Ureta, Bermejo Vera, Rivero Ortega, Parejo Alfonso, Rebollo Puig, Fernández Ramos y Muñoz Machado. ${ }^{57}$

La función que se ejecuta el auditor interno a partir de los principios de descentralización y desconcentración, quien realiza esta labor en las formas de

57 ESTEVE PARDO, José, Derecho del medio ambiente y Administración Local, Editorial Fundación Democrática y Gobierno Local, $2^{\text {da }}$ edición, Madrid, 2004;SÁNCHEZ MORÓN, Miguel, El control de las Administraciones Públicas y sus problemas, Editorial Espasa- Calpe S.A, Madrid, 1991; GARCÍA URETA, Agustín, "Potestad inspectora y medio ambiente: Derecho de la Unión Europea y algunos datos sobre las Comunidades Autónomas" en, Revista Actualidad Jurídica Ambiental, número 54, España, 2006; BERMEJO VERA, José, La Administración inspectora, Revista de Administración Pública, número 147, España, 1998; RIVERO ORTEGA, Ricardo, El Estado vigilante. Consideraciones jurídicas sobre la función inspectora de la Administración, Editorial Tecnos, Madrid, 2000, PAREJO ALFONSO, Luciano, El derecho al medio ambiente y la actuación de la Administración Pública, Editorial Aranzadi, España, 2013; REBOLLO PUIG, Manuel, La actividad inspectora, Editorial Iustel, España, 2011; FERNÁNDEZ RAMOS, Severiano, La inspección ambiental, Revista del Medio Ambiente y la Administración Local, España, 2010; EMBID IRUJO, Antonio, "El rol del Estado: Vigilanteo Gestor" en, Revista de Política Ambiental y Desarrollo Sostenible, Madrid, 1999; MIRANDA HERNÁNDEZ, Gloria, La potestad inspectora de las Administraciones Públicas, Revista Cuadernos de Inspección del Territorio, España, 2012; DIEZ SÁNCHEZ, José, Función inspectora, $1^{\text {ra }}$ edición, Instituto de Administración Pública, España, 2013; GARCÍA MARCOS, José, La inspección ambiental y el derecho comunitario europeo, Revista Ambiente \& Derecho, número 26-27, España, 2014. 
gestión del sector estatal, con muchos retos aún por alcanzar, visibles en la comprobación ejecutada con una periodicidad anual para constatar el estado del control interno en el país rectorado por la CGR con el auxilio de organismos de la Administración Pública, cuyo objetivo es fortalecer la gobernanza estatal a las formas de gestión de cada organismo, que permita contar con un diagnóstico de su estado en materia de control administrativo, en pos de alcanzar la perfección como meta, la que tiene carácter obligatorio como lo establece el Decreto Ley No. 159 de 1995, que a criterio de Antúnez Sánchez es la Ley de la Auditoría Pública en la nación cubana. ${ }^{58}$

Es importante a partir de la valoración de los autores, que este control administrativo, ejecutado a través de la auditoría puede ejecutarse como actividad de control y como un servicio público, apreciamos como la tendencia en el desarrollo normativo cubano ha sido regularla de manera obligatoria como Estado policía, al ser mayoría los sujetos de gestión del sector estatal; pero que sucede con el reconocimientos de las formas de gestión privada, aquí nos detenemos al considerar el criterio aportado por Matilla Correa ${ }^{59}$, quien señala que pudiera ser considerada también como un servicio público, aún sin una construcción adecuada desde las ciencias jurídicas en el país.

Ello permite cerrar a los autores incentivando a los interesados en el estudio del control administrativo, en seguir el estudio de las funciones atributivas al

58 ANTÚNEZ SÁNCHEZ, Alcides, Actualización del modelo económico cubano para el ordenamiento jurídico en el desarrollo del Derecho Ambiental patrio, Revista Multiciencias, número 3, Venezuela, 2015.

59 MATILLA CORREA, Andry, Derecho Administrativo y servicio público. Trazos inconclusos desde una perspectiva histórica, Revista Jurídica UNAM, México D.F. órgano de control, de los mecanismos que utiliza en su actuación, de los principios desde la ciencias del Derecho y desde las ciencias Contables que son observados mientras se practica la inspección, la fiscalización, el control gubernamental y la auditoría pública para el control del patrimonio estatal que hoy trasciende a la dimensión ambiental.

\section{CONSIDERACIONES FINALES}

El control público en la nación cubana ha sido ejecutado indistintamente por órganos de control y organismos de la Administración Pública, ejecutados a través procesos y procedimientos a través de la función inspectiva y la auditoría, dirigidos en esencia al sector estatal a partir del triunfo de la Revolución para el control del patrimonio al ser este quien posee mayores sujetos de gestión.

La Contraloría General de la República, su asidero jurídico no está concebido de manera adecuada, toda vez que dentro del texto constitucional solo aparecen reconocidos como órganos el Tribunal Supremo y la Fiscalía General de la República.

En el ordenamiento jurídico patrio coexisten dos normas jurídicas que establecen la auditoría pública, lo que genera un conflicto de ley, lo adecuado hubiera sido que el legislador hubiera derogado de manera tácita el Decreto Ley No. 159 de 1995 cuando se promulgó la Ley No. 107 de 2009 y se hubiera concebido su Reglamento, lo cual no fue ejecutado.

Es una necesidad actualizar la Ley No. 107 de 2009, la que establece que el control administrativo a través de la auditoría pública es de forma obligatoria, dejando fuera el reconocimiento al sector privado, donde la tendencia internacional es que 
este sujeto económico solicite este tipo de control por interés personal.

Es necesario atemperar para la exigencia de la responsabilidad administrativa el Decreto No. 228 de 1997, el mismo no recoge la exigencia de este tipo de responsabilidad para los tipos de auditorías que se establecen en el Reglamento de la Ley No. 107 de 2010 en vigor de la Ley No. 107 de 2009.

En la actualización de la Ley No. 107 de 2009, deberá valorarse dos niveles de atención a las inconformidades ante los resultados del control administrativo, uno inicial en la vía administrativa interna y otro en la vía jurisdiccional en la sala de lo administrativo, tal y como se reconoce en la doctrina del Derecho Público.

\section{REFERENCIAS BIBLIOGRÁFICAS}

Aldunate L., E. 2005. "La evolución de la función de control de la Contraloría General de la República". Revista de Derecho de la Pontificia Universidad Católica de Valparaíso. XXVI. Chile: 19-30.

Antúnez Sánchez, A. 2015. "La auditoría practicada por la Contraloría General de la República de Cuba. Las formas de actividad administrativa en la actualización del modelo económico cubano para el futuro ordenamiento jurídico en el desarrollo del Derecho Ambiental patrio". Revista Temas Socio-Jurídicos. 68. Colombia: 25-37.

Antúnez Sánchez, A. 2015. "Actualización del modelo económico cubano para el ordenamiento jurídico en el desarrollo del Derecho Ambiental patrio". Revista Multiciencias. 3. Venezuela.

Antúnez Sánchez, A. 2015. "Disquisiciones teóricas, doctrinales y exegéticas sobre la praxis de la auditoría como función pública, dirigida a la protección del bien público ambiental para la empresa ecológica". Revista Dos Tribunais Thomson Reuters. 951. Brasil.

Aguiló Regla, J. 2000. "Derogación, rechazo y sistema jurídico". Revista Informática y Derecho.
Alvarado Riquelme, M. 2014. Teoría y práctica de la auditoría. España: Ediciones Pirámide.

Alenza García, J. 2005. Potestad de Inspección. Muñoz Machado, S. (coordinador). Diccionario de Derecho Administrativo. Madrid. Ediciones Iustel.

Almeida Cerreda, M. 2008. ¿Es necesario un nuevo modelo de controles sobre los entes locales? REAF: 187-232.

Arias Gayoso, G. 2014. Del nuevo Derecho Administrativo: Participación y control popular en la gestión pública. Participación Política, reflexiones desde el Sur. Ecuador. Ediciones Advantlogic.

Arias Gayoso, G. 2014. La lógica de un dilema: del control de la Administración Pública al control del ejercicio de la discrecionalidad administrativa. México. Ediciones UNAM.

Béjar Rivera, L. 2011. El acto administrativo y su finalidad. México. Ediciones Porrúa.

Berro, G. 1992. "Responsabilidad objetiva del Estado". Revista de Derecho Público. 2. Montevideo: 89 y ss.

Cagnoni, J. 1996. Introducción a la Teoría del Control. Montevideo. Ediciones Universidad de Montevideo.

Cagnoni, J. 1999. "Una lección sobre control". Revista de Derecho Público. 15. Ediciones FCU, Montevideo: 121 y ss.

Cantón Navarro, J.; Duarte Hurtado, M. 2006. Cuba 42 años de Revolución. Cronología histórica 1959-1982. La Habana. Ediciones Ciencias Sociales.

Canals I.; Ametller, D. 2003. El Ejercicio por Particulares de Funciones de Autoridad (control, inspección y certificación). Granada. Ediciones Comares.

Castillo Téllez, C. 2014. Memoria histórica de la Oficina Nacional de Auditoría y del Ministerio de Auditoría y Control. La Habana. Contraloría General de la República.

Coopers \& Lybrand. 1997. Los nuevos conceptos de control interno. España. Ediciones Días de Santos.

Cordero Vega, L. 2007. El Control de la Administración del Estado. Chile. Ediciones Lexis Nexis. 
Delpiazzo Rodríguez, C. 1982. Tribunal de Cuentas. Montevideo. Ediciones Amalio Fernández.

Delpiazzo Rodríguez, C. 2001. Desafíos actuales del control. Montevideo. Ediciones FCU: 138.

Dromi, R. 2005. Modernización del Control Público. Madrid: Ediciones Hispania Libros.

Delgadillo Gutiérrez, L. 2011. El sistema de responsabilidades de los servidores públicos. México: Ediciones Porrúa.

De Luca, J. 1997. Introducción al Derecho. España. Ediciones Tirant Lo Blanch.

Duguit, L. 1975. Las transformaciones generales del Derecho (Público y Privado), traducción de Adolfo Posada y Ramón. Jaén. Argentina. Ediciones Heliasta S.R.L. 105.

Esteve Pardo, J. 2011. Lecciones de Derecho Administrativo. España. Ediciones Marcial Pons: 3-27.

Embid Irujo, A. 1999. "El rol del Estado: Vigilante o Gestor". Revista de Política Ambiental y Desarrollo Sostenible. Madrid.

Fernández Bulté, J. 2003. Historia del Estado y del Derecho. La Habana. Ediciones Félix Varela.

Fernández Bulté, J. 2002. Teoría del Estado y el Derecho en Cuba. La Habana. Ediciones Félix Varela.

Ferrada, J. 2000. El principio de control en la Administración del Estado. La Administración del Estado de Chile. Decenio 19902000. Chile. Ediciones Conosur: 593-634.

Ferrajoli, L. Derecho y Razón, 2001. Madrid. Editorial Trotta.

Hernández, J. 2000. "La Contraloría General de la República". Revista de Derecho Público. 83. Venezuela.

Hart, H. 1999. Teoría del Derecho. Argentina. Ediciones Abeledo Perrot S.A.

Hauriou, M. 1925. Principios de derecho público y constitucional. Madrid. Ediciones Reus: 187.

Garrido Falla, F.1958. Las transformaciones del concepto jurídico de policía administrativa. España. Ediciones Instituto de Estudios Políticos.
García de Enterría, E. 2006. Curso de Derecho Administrativo. España. Ediciones Thompson-Civitas.

García Ureta, A. 2006. La Potestad Inspectora de las Administraciones Públicas. Barcelona. Ediciones Marcial Pons.

Garcini Guerra, H. 1986. Derecho Administrativo. La Habana. Ediciones Pueblo y Educación.

Gordillo, A. 2006. Tratado de Derecho Administrativo. Argentina. Ediciones Macchi.

Gezze, G. 1956. Principios generales del Derecho Administrativo. Buenos Aires. Ediciones de Palma.

Giménez Icarrons, E. 2001. Los controles administrativos sobre los entes locales, Generalitat de Catalunya. Madrid. Ediciones Jurídicas y Sociales S.A.293.

Mayer, O. 1982. Derecho Administrativo Alemán. Buenos Aires. Ediciones Depalma.

Márquez Piñeiro, R. 2003. Teoría de la antijuricidad. Instituto de Investigaciones Jurídicas-UNAM.

Matilla Correa, A. 2009. (Coord.) Panorama de la Ciencia del Derecho en Cuba, Estudios en homenaje al profesor Dr. Julio Fernández Bulté, Lleonard Muntanar, Palma de Mallorca, 2009.

Muñoz Machado, M. 2011. Tratado de Derecho Administrativo y Derecho Público General. España. Ediciones Iustel.

Martín-Retortillo Baquer, L. 1997. "Poder Ejecutivo, discrecionalidad, legalidad y control". Revista del Poder Judicial. 6. Consejo General del Poder Judicial Madrid. 215-252.

Márquez Gómez, D. 2002. Los Procedimientos Administrativos materialmente jurisdiccionales como medios de control en la Administración Pública. Universidad Nacional Autónoma de México.

Nieto, A. 1976. "Algunas precisiones sobre el concepto de policía". Revista de Administración Pública. 81. España.

Rebollo Puig, M. 1999. "La peculiaridad de la policía administrativa y su singular adaptación al principio de legalidad". Revista Vasca de Administración Pública. 54. España.

Rivero Ortega, R. 2000. El Estado vigilante. Madrid. Ediciones Tecnos. 79-85. 
Rodríguez Azcué, G. 2002.El control del Tribunal deCuentas y losauditores gubernamentales, Aspectos Administrativos en las Leyes "de urgencia" y de Presupuesto (Nos. 17.243 17.292 - 17.296) en Homenaje a la Memoria del Prof. Héctor Barbé Pérez, Montevideo, 2002. 385 y ss.

Parada, R. 1997. Derecho Administrativo. España. Ediciones Marcial Pons.

Peña Solís, J. 2003. La actividad de la Administración Pública: de policía administrativa, de servicio público, de fomento y de gestión económica, Manual de Derecho Administrativo. Caracas. Ediciones Colección de Estudios Jurídicos del Tribunal Supremo. 107 y ss.

Parejo Alfonso, L. 2013. Derecho de los bienes públicos. Cizur Menor. Ediciones Aranzadi.

Posada, A. 1931. Tratado de Derecho Administrativo. Ediciones Madrid.

Pozo Ceballos, S. 2011. "Naturaleza y papel de la Contraloría General de la República de Cuba dentro del sistema de control externo". Revista electrónica de Contabilidad y Finanzas COFIN. La Habana.

Portuondo del Prado, F. 1965. Historia de Cuba 1492-1898. La Habana. Ediciones Instituto Cubano del Libro.

Puerres, I. 2011. "Naturaleza de la auditoría". Revista de la Universidad Complutense de Madrid. 7.

Sánchez Morón, M. 1991. El control de las Administraciones Públicas y sus problemas. Madrid. Ediciones Espasa-Calpe S.A. 40.

Jordana de Pozas, L. 1949. "Ensayo de una teoría del fomento en el Derecho Administrativo". Revista de Estudios Políticos. 48. España.
Torres Cuevas, E. 2007. 1492-1898. Historia de Cuba, formación y liberación de la nación. La Habana. Ediciones Félix Varela.

Lanz Cárdenas, J. 1987. La contraloría y el control interno en México. México. Ediciones Fondo de Cultura Económica.

Lozano Miralles, J. 1996. Configuración e independencia de los Órganos de Control Externo: un análisis comparado. España. Editorial Civitas.

López Hernández, A. 2013. "Normas profesionales de la INTOSAI: directrices de auditoría". Revista Auditoría Pública. 61. Granada.

Juárez Jonapa, J. 2012. Teoría General del Estado. México. Ediciones Red Tercer Milenio.

Kelsen, H. 1980. "Teoría Pura del Derecho y Teoría Ecológica". Revista de Derecho UNAM. México.

Valadés, D. 2011. El control del Poder. Biblioteca Jurídica UNAM. Villar Palasí, J. 1950. "La actividad administrativa industrial del Estado en el Derecho Administrativo". España. Revista de Administración Pública. 3.

Villardefrancos Álvarez, M. 2006. "La auditoría como proceso de control: concepto y tipología". Revista Ciencias de la Información. 37. Cuba.

Vázquez Alfaro, J. 1996. El control de la Administración Pública en México. Ediciones Universidad Nacional Autónoma de México.

Antúnez-Sánchez, A., \& Ramírez-Sánchez, A. (2016). La Contraloría General de la República de Cuba. Panorama Económico, 24, 175-204.

AUTORES

Alcides Antúnez-Sánchez

Licenciado en Ciencias Penales. INSTITUTO SUPERIOR DEL MINISTERIO DEL INTERIOR.

La Habana. Cuba. Licenciado en Derecho de la Universidad de Granma (Cuba). Máster en Asesoría Jurídica. Universidad de Oriente. Profesor Auxiliar Derecho Ambiental $€$ Internacional en el Departamento de Derecho, Facultad de Ciencias Económicas y Sociales de la misma universidad.

Amed Ramírez-Sánchez

Licenciado en Derecho. Máster en Derecho Constitucional y Administrativo de la Universidad de Oriente. Máster en Derecho Constitucional de la Universidad Internacional Menéndez Pelayo y el Centro de Estudios Políticos y Constitucionales de Madrid. Profesor Asistente en la Universidad de Granma (Cuba). 

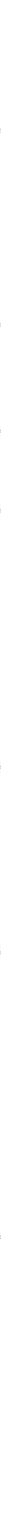

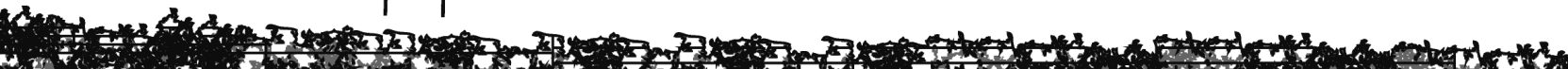

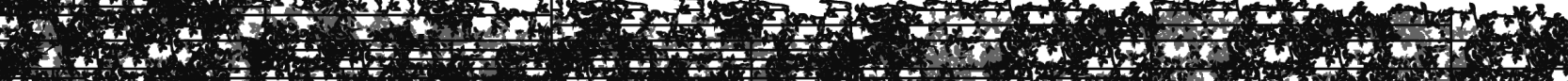
N.t. 